\title{
Bisphenol A and its analogues disrupt centrosome cycle and microtubule dynamics in prostate cancer
}

\author{
Shuk-Mei Ho1,2,3,4, Rahul Rao1, Sarah To1,5,6, Emma Schoch1 and Pheruza Tarapore1,2,3 \\ 'Department of Environmental Health, University of Cincinnati Medical Center, Cincinnati, Ohio, USA \\ ${ }^{2}$ Center for Environmental Genetics, University of Cincinnati Medical Center, Cincinnati, Ohio, USA \\ ${ }^{3}$ Cincinnati Cancer Center, Cincinnati, Ohio, USA \\ ${ }^{4}$ Cincinnati Veteran Affairs Hospital Medical Center, Cincinnati, Ohio, USA \\ ${ }^{5}$ Center for Cancer Research, Hudson Institute of Medical Research, Clayton, Victoria, Australia \\ ${ }^{6}$ Monash University, Clayton, Victoria, Australia
}

Correspondence

should be addressed

to S-M Ho or P Tarapore

Email

shuk-mei.ho@uc.edu or pheruza.tarapore@uc.edu

\begin{abstract}
Humans are increasingly exposed to structural analogues of bisphenol A (BPA), as BPA is being replaced by these compounds in BPA-free consumer products. We have previously shown that chronic and developmental exposure to BPA is associated with increased prostate cancer ( $\mathrm{PCa}$ ) risk in human and animal models. Here, we examine whether exposure of PCa cells (LNCaP, C4-2) to low-dose BPA and its structural analogues (BPS, BPF, BPAF, TBBPA, DMBPA and TMBPA) affects centrosome amplification (CA), a hallmark of cancer initiation and progression. We found that exposure to BPA, BPS, DMBPA and TBBPA, in descending order, increased the number of cells with CA, in a nonmonotonic dose-response manner. Furthermore, cells treated with BPA and their analogues initiated centrosome duplication at $8 \mathrm{~h}$ after release from serum starvation, significantly earlier in G-1 phase than control cells. This response was attended by earlier release of nucleophosmin from unduplicated centrosomes. BPA-exposed cells exhibited increased expression of cyclin-dependent kinase CDK6 and decreased expression of CDK inhibitors ( $221_{\text {Waf1/CIP1 }}$ and $p 27^{K I P 1}$ ). Using specific antagonists for estrogen/androgen receptors, CA in the presence of BPA or its analogues was likely to be mediated via ESR1 signaling. Change in microtubule dynamics was observed on exposure to these analogues, which, for BPA, was accompanied by increased expression of centrosome-associated protein CEP350. Similar to BPA, chronic treatment of cells with DMBPA, but not other analogues, resulted in the enhancement of anchorage-independent growth. We thus conclude that selected BPA analogues, similar to BPA, disrupt centrosome function and microtubule organization, with DMBPA displaying the broadest spectrum of cancer-promoting effects.
\end{abstract}

Endocrine-Related Cancer (2017) 24, 83-96

\section{Introduction}

Bisphenol A (BPA), a prototype endocrine-disrupting chemical (EDC), is a mimic of estrogen present in polycarbonate plastic products, thermal paper and carbonless copy paper. Its leakage from these products results in its ubiquitous presence at significant levels in the environment. Its effects suggest that it can reprogram the developing human and animal tissues, particularly those sensitive to hormones such as the prostate 
(Ho et al. 2011, Ho et al. 2012). As a result, alternatives to BPA are being developed and are increasingly replacing BPA. Bisphenol S (BPS) is used as a chemical additive in thermal paper, pesticides, dyestuffs, color-fast agents, leather tanning agents, dye dispersants and fiber improvers. Considering that BPS is less biodegradable than BPA (Ike et al. 2006, Danzl et al. 2009), the widespread use of BPS is of concern. The halogenated derivative of BPA, such as tetrabromobisphenol A (2,2-bis(4-hydroxy3,5-dibromophenyl)propane, (TBBPA)) is widely used in flame-retardants for building material, paints and epoxy resin-containing plastic products such as electronic circuit boards and other electronic equipment (Kitamura et al. 2005). Other less well-studied BPA structural analogues such as bisphenol $\mathrm{F}$ (BPF), bisphenol AF (BPAF), tetramethyl bisphenol A (TMBPA) and 3,3'-dimethylbisphenol A (DMBPA) are also increasingly used as BPA replacement materials in polycarbonate resin (Kitamura et al. 2005).

Alarmingly, structural analogues of BPA have already been detected in foods (Vinas et al. 2010, GallartAyala et al. 2011), indoor dust (Wang et al. 2015), thermal receipt papers (Becerra \& Odermatt 2012, Liao et al. 2012b), sewage sludge (Song et al. 2014, Ruan et al. 2015) and human bodily fluids (Cariou et al. 2008, Fernandez et al. 2008, Johnson-Restrepo et al. 2008, Jimenez-Diaz et al. 2010, Yang et al. 2014, Zhou et al. 2014). For example, BPS (free and conjugated) has been detected in $81 \%$ of urine samples from the general population collected from USA and seven Asian countries $(n=315$; (Liao et al. 2012a)). It is well documented that higher levels of BPA exposure is associated with increased risk of cardiovascular disease, obesity, diabetes, immune disorders and a host of reproductive dysfunctions (Keri et al. 2007, vom Saal et al. 2007, Ho et al. 2012, Rogers et al. 2013, Zawatski and Lee 2013). At this juncture, as we rapidly introduce BPA substitutes in consumer products, the pressing question that remains to be answered is the adverse health effects of these analogues due to their structural similarity to BPA.

Amplification of centrosomes is one of the early hallmarks of cancer initiation and progression (Godinho \& Pellman 2014). During interphase, microtubules (MTs) arising from the centrosome maintain the tissue architecture, polarity and organelle transport. The centrosome also directs the formation of bipolar mitotic spindles, which is essential for accurate chromosome segregation to daughter cells (reviewed in Tarapore and Fukasawa 2000). Upon cytokinesis, each daughter cell inherits only one centrosome from a mother cell, and thus, the centrosome must duplicate once in each cell cycle, in synchrony with other cell cycle events including
DNA synthesis. In mammalian cells, the centriole, the core component of the centrosome, initiates duplication at the G1/S boundary (reviewed in Mazia 1987). Regulation of centrosome duplication is very tightly controlled, and any disturbance in this process can lead to abnormalities in the centrosome cycle and function.

We recently found that higher urinary BPA was found in PCa patients when compared to non-PCa subjects (Tarapore et al. 2014). Additionally, exposure of immortalized normal prostate epithelial cell lines (NPrEC and RWPE-1) and four PCa cell lines (LNCaP, C4-2, 22Rv1 and PC-3) to low-dose BPA (pmole range) increased centrosome amplification (CA), promoted MT nucleation and regrowth at centrosomes and enhanced anchorageindependent growth (Tarapore et al. 2014); all these cellular processes are well-accepted markers of cancer initiation and progression (Pihan et al. 2001, Lingle et al. 2002, Pihan et al. 2003, Mori et al. 2009, Ogden et al. 2013). Extending on our BPA study, here we examined whether exposure to low-dose BPA analogues (BPS, BPF, BPAF, TBBPA, TMBPA and DMBPA) has comparable effects as BPA on these cancer-related processes. We found that most of them exert similar, but not completely comparable action, as BPA. However, it appears that DMBPA, like BPA, has an effect on both CA and anchorageindependent growth.

\section{Materials and methods}

\section{Cell lines}

The prostate cancer (PCa) cell lines LNCaP and C4-2 (between passages 19 and 35) were obtained from the American Type Culture Collection (ATCC) and cultured in RPMI-1640 (Corning) with 10\% FBS and supplements recommended under standard conditions. RWPE-1 cell lines were purchased from ATCC and cultured in Defined Keratinocyte-SFM medium (ThermoFisher Scientific) with growth-promoting supplement. Cells were maintained at $37^{\circ} \mathrm{C}$ in a humidified incubator with a $5 \% \mathrm{CO}_{2}$ atmosphere. These cell lines have been authenticated by ATCC using STRS analysis.

\section{BPA and analogue treatments}

LNCaP and C4-2 cell lines were seeded in 6-well plates with coverslips at 20,000 cells/mL. After $24 \mathrm{~h}$, cells were rinsed with PBS and maintained in phenol red-free RPMI1640 with $10 \%$ charcoal-stripped serum (CSS) for another $24 \mathrm{~h}$. After this incubation period, media was replaced with fresh $10 \%$ CSS media and cells were treated with BPA,

Published by Bioscientifica Ltd. 
BPF, BPAF, BPS, TBBPA, DMBPA and TMBPA (Sigma) to a final concentration of $0,0.01,0.1,1,10$ or $100 \mathrm{nM}$. For the time-point experiment, cells grown in $35 \mathrm{~mm}$ wells with coverslips were serum starved using phenol red-free RPMI1640 with $0.05 \%$ CSS for $48 \mathrm{~h}$. At time-points $0,8,16,24$, 32 and $40 \mathrm{~h}$, media was changed to phenol red-free RPMI1640 with $20 \%$ CSS \pm BPA analogues at concentrations which gave the maximum effects.

To investigate whether CA by BPA, BPS, TBBPA and DMBPA was dependent on nuclear receptors estrogen receptor $\alpha(\mathrm{ER} \alpha / \mathrm{ESR} 1), \mathrm{ER} \beta / \mathrm{ESR} 2$, androgen receptor $(\mathrm{AR})$ or $\mathrm{G}$ protein-coupled estrogen receptor (GPER1/GRP30), cells were seeded and placed in phenol red-free RPMI1640 with $10 \%$ CSS as described above. After 24-48h, media was replaced with fresh $10 \%$ CSS medium with $1 \mu \mathrm{M}$ final concentrations of inhibitors (from Tocris, Minneapolis, MN, USA), Fulvestrant/ICI-182,780, MPP (1,3-bis(4-hydroxyphenyl)-4-methyl-5-[4-(2piperidinylethoxy)phenol]-1H-pyrazole dihydrochloride), PHTPP (4-[2-phenyl-5,7-bis(trifluoromethyl) pyrazolo[1,5-a]pyrimidin-3-yl]phenol) bicalutamide, G15 ((3aS*,4R*,9bR*)-4-(6-bromo-1,3-benzodioxol-5-yl)$3 \mathrm{a}, 4,5,9 \mathrm{~b}-3 \mathrm{H}$-cyclopenta[c]quinolone) in the presence and absence of $0.1 \mathrm{nM}$ BPA, $0.1 \mathrm{nM}$ BPS, $0.01 \mathrm{nM}$ TBBPA and $0.01 \mathrm{nM}$ DMBPA for $72 \mathrm{~h}$.

\section{Indirect immunofluorescence}

Cells were fixed using $100 \%$ methanol at $-20^{\circ} \mathrm{C}$ for $5 \mathrm{~min}$ and processed as described previously (Tarapore et al. 2012) with $\gamma$-tubulin antibody (clone GTU88 antibody, Sigma), anti-pericentrin (Anti-PCNT Rabbit polyclonal, Sigma Prestige Antibodies HPA016820) along with anti-centrin antibody (clone $20 \mathrm{H} 5$ antibody, Millipore and Santa Cruz sc-50452). Cells were immunostained for centrioles as well as for centrosomes in the same slide. When the number of centrosome $=2$, number of centrioles is 3 or 4 . For NPM analysis, cells were fixed using 10\% formalin:acetic acid at $25^{\circ} \mathrm{C}$ for $20 \mathrm{~min}$. Cells were permeabilized with $0.7 \%$ Triton-X at $25^{\circ} \mathrm{C}$ for $2 \mathrm{~min}$, double-stained for gammatubulin (clone GTU88) or centrin and nucleophosmin (Abcam ab15440 rabbit polyclonal). Antibodies were detected with Alexa Fluor conjugated fluorescent antibodies. Nuclear staining was performed using 4',6-diamidino-2-phenylindole (DAPI, ThermoFisher).

\section{Anchorage-independent growth assay}

Anchorage-independent growth was measured by assessing the efficiency of colony formation in a semi- solid medium. Cells were first chronically exposed to BPA analogues for $\sim 10$ passages. Concentrations used were as follows: For LNCaP BPA $0.1 \mathrm{nM}$, BPS $0.1 \mathrm{nM}$, TBBPA $0.01 \mathrm{nM}$, DMBPA $0.1 \mathrm{nM}$, TMBPA $0.1 \mathrm{nM}$; for C4-2 BPA $0.1 \mathrm{nM}$, BPS $0.1 \mathrm{nM}$, TBBPA 0.01 nM, DMBPA $0.01 \mathrm{nM}$ and TMBPA $0.1 \mathrm{nM}$. Approximately 2500 cells $/ 35 \mathrm{~mm}$ well were then embedded in soft agar. Medium was refreshed twice a week with and without BPA analogues. After 2-3 weeks, colonies were counted under a microscope. All conditions were performed in triplicate and repeated twice. Colony-forming efficiency was calculated as the number of colonies counted divided by the total number of cells plated, multiplied by 100 .

\section{Quantitative real-time RT-PCR (qPCR) for gene expression}

Total RNA $(1 \mu \mathrm{g})$ from LNCaP and C4-2 cells treated with BPA as described above, was reverse-transcribed using SMARTscribe Reverse Transcriptase (Clontech) and

Table 1 Details of qRT-PCR primers.

\begin{tabular}{|c|c|c|}
\hline Transcript & Primer name & Sequence $\left(5^{\prime}-3^{\prime}\right.$ direction $)$ \\
\hline \multirow[t]{2}{*}{ p53 } & hu-p53-F & CGTCTGGGCTTCTTGCATTCT \\
\hline & hu-p53-R & AGCTGCACAGGGCAGGTCTT \\
\hline \multirow[t]{2}{*}{ CDK4 } & hu-CDK4-F & CTTCTGCAGTCCACATATGCAACA \\
\hline & hu-CDK4-R & CAACTGGTCGGCTTCAGAGTTTC \\
\hline \multirow[t]{2}{*}{ CDK6 } & hu-CDK6-F & TGGTGACCAGCAGCGGACAA \\
\hline & hu-CDK6-R & ACCACAGCGTGACGACCACT \\
\hline \multirow[t]{2}{*}{ CDK2 } & hu-CDK2-F & CCAGGAGTTACTTCTATGCCTGA \\
\hline & hu-CDK2-R & TTCATCCAGGGGAGGTACAAC \\
\hline \multirow{2}{*}{$\begin{array}{l}\text { p21Waf1 } \\
\text { (CDKN1A) }\end{array}$} & hu-p21-F & GAGGAAGACCATGTGGACCTGT \\
\hline & hu-p21-R & GCGGATTAGGGCTTCCTCTTG \\
\hline \multirow{2}{*}{$\begin{array}{l}\text { p27KIP1 } \\
\text { (CDKN1B) }\end{array}$} & hu-p27-F & GCAACCGACGATTCTTCTACTCAAA \\
\hline & hu-p27-R & GCTTCATCAAGCAGTGATGTATCT \\
\hline \multirow[t]{2}{*}{ cyclin A2 } & hu-CCNA2-F & GGGACAAAGCTGGCCTGAATC \\
\hline & hu-CCNA2-R & AGTGTCTCTGGTGGGTTGAGGA \\
\hline \multirow[t]{2}{*}{ cyclin E1 } & hu-CCNE1-F & AGTGTCTCTGGTGGGTTGAGGA \\
\hline & hu-CCNE1-R & GCTTGCACGTTGAGTTTGGGTA \\
\hline \multirow[t]{2}{*}{ cyclin D1 } & hu-CCND1-F & CCGTCCATGCGGAAGATC \\
\hline & hu-CCND1-R & ССTССTCСTCGCACTTCTGT \\
\hline \multirow{2}{*}{$\begin{array}{l}\text { p150glued } \\
\text { (DCTN1) }\end{array}$} & hu-DCTN-F & CACTTGTGATGAAGGGCATGG \\
\hline & hu-DCTN-R & ATCAGTTCCCTCTCTTTTGAGGAC \\
\hline \multirow{2}{*}{$\begin{array}{l}\text { EB1 } \\
\text { (MAPRE1) }\end{array}$} & hu-MAPRE-F & CAGAGGCCCATCTCAACACA \\
\hline & hu-MAPRE-R & CAATACGTTGACCTGCTGCAT \\
\hline \multirow[t]{2}{*}{ Ninein (NIN) } & hu-NIN-F & ACTATATCCGGGACCGCCTT \\
\hline & hu-NIN-R & CGAGGTCACCAAACTTTTCTGC \\
\hline \multirow[t]{2}{*}{ CEP150 } & hu-CEP350-F & TAGCAGCCGCCAAGAAAGTC \\
\hline & hu-CEP350-R & GACGTTGAGTCTTTTTCATCAGGA \\
\hline \multirow[t]{2}{*}{ RPS3 } & hu-RPS3-F & AGCCACCAGAACACAGAATG \\
\hline & hu-RPS3-R & CTAGTGGCCACCTTTTCAGC \\
\hline
\end{tabular}

Forward and reverse primers were designed to overlap atleast one exon-exon boundary of the target gene. The primer positions are based on the reference sequence of the target genes in the GenBank. Expression of ribosomal protein 3 gene (RPS3) or GAPDH (for CCNA2) was used as control for sample normalization in the quantification of the gene of interest expression by real-time RT-PCR analysis.

Published by Bioscientifica Ltd. 
A
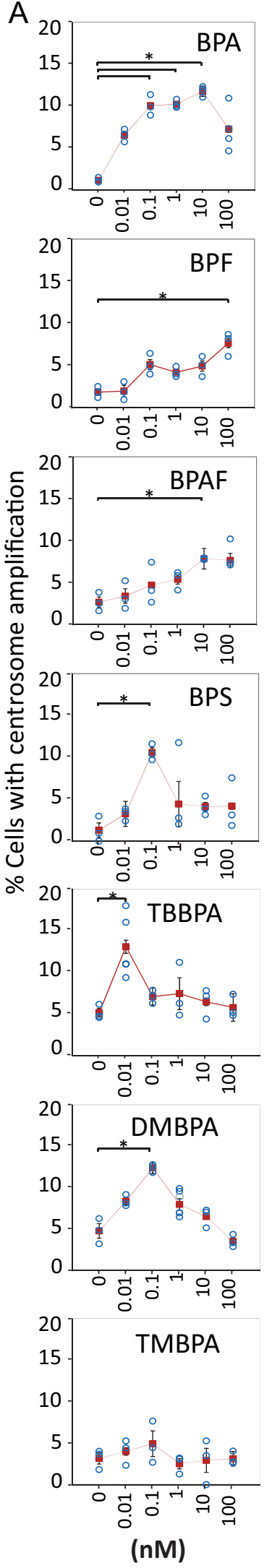

LNCaP
$\mathrm{B}_{20}$
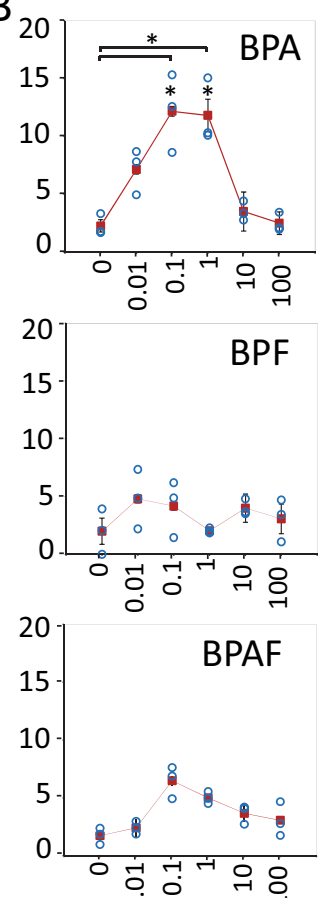
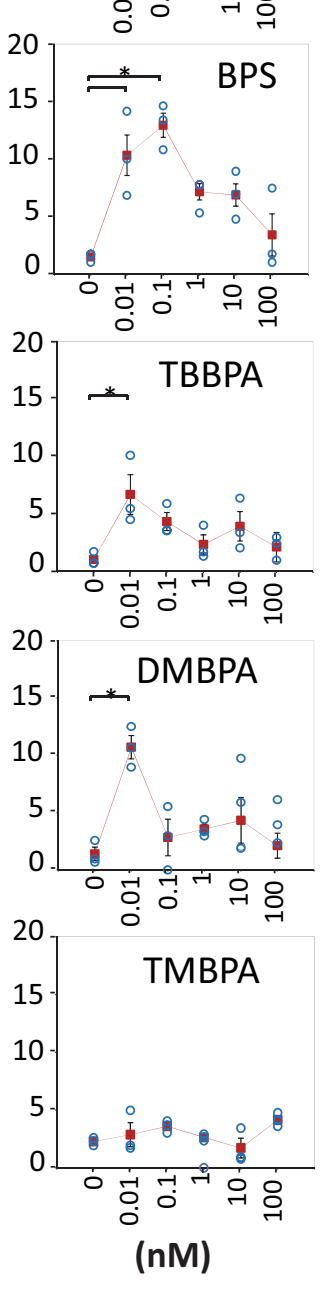

C4-2 random hexamers (Promega). Amplification was detected using PerfeCTa SYBR Green FastMix, Low ROX reagent (Quanta Biosciences, Gaithersburg, MD, USA) using the ViiA 7 Real-Time PCR System (ThermoFisher). Primer sequences are listed in Table 1 . The target gene expression was normalized against the individual endogenous RPS3, and the relative change in transcript level was calculated with the delta-delta CT method.

\section{MT-Aster formation}

To examine the effect of BPA analogues on MT-aster formation, cells were treated for 3 days with concentrations as follows: For LNCaP BPA $0.1 \mathrm{nM}$, BPS $0.1 \mathrm{nM}$, TBBPA $0.01 \mathrm{nM}$, DMBPA $0.1 \mathrm{nM}$, TMBPA $0.1 \mathrm{nM}$; for C4-2 BPA $0.1 \mathrm{nM}$, BPS $0.1 \mathrm{nM}$, TBBPA $0.01 \mathrm{nM}$, DMBPA $0.01 \mathrm{nM}$, TMBPA $0.1 \mathrm{nM}$. Cells were then treated with nocodazole (Sigma, $1.5 \mu \mathrm{g} / \mathrm{mL}$ ) for $40 \mathrm{~min}$ on ice to depolymerize the interphase MTs. Cells were rinsed to remove the nocodazole, and then cells were incubated in fresh warm medium for $7 \mathrm{~min}$ at $37^{\circ} \mathrm{C}$ to allow for MT regrowth. Cells were fixed with methanol at room temperature and stained for centrosomes (anti- $\gamma$-tubulin Sigma GTU88 T6557 mouse monoclonal; anti- $\gamma$-tubulin Santa Cruz, CA C-20 sc7396 goat polyclonal) and MTs (anti-alpha-tubulin Santa Cruz DM1A sc32296 mouse monoclonal). Cells were scored ( $\sim 300$ cells counted) for MT-aster formation.

\section{Statistical analysis}

All in vitro experiments were performed in triplicate and repeated 3 times. Values are reported as fold change \pm S.E.M. Statistical significance was tested by two-tailed Student's $t$-test. $P$-values $\leq 0.05$ were considered significant $\left({ }^{*} P \leq 0.05\right.$; $\left.{ }^{* *} P \leq 0.01 ;{ }^{* *} P \leq 0.001\right)$.

\section{Results}

Exposure to low-dose BPA, BPS, TBBPA and DMBPA promotes centrosome amplification (CA) in a non-linear manner

Androgen-dependent (AD; LNCaP) and -independent (AI; C4-2) prostate cells were treated with low-dose

\section{Figure 1}

Low doses of BPA, BPS, TBBPA and DMBPA promote CA: LNCaP (A) and C4-2 (B) cell lines were treated with various doses of BPA, BPF, BPAF, BPS, TBBPA, DMBPA or TMBPA for $72 \mathrm{~h}$ in $10 \%$ CSS media. Cells were fixed and immunostained for centrosomes and DNA. Using fluorescence microscopy, cells with amplified centrosomes were scored and plotted for each dose of $0,0.01,0.1,1,10$ and $100 \mathrm{nM}$. Significance was determined using the Student's $t$-test $\left({ }^{*} P<0.05\right)$. Bars, S.E. of the three independent experiments.

Published by Bioscientifica Ltd. 
levels of BPA, BPF, BPAF, BPS, TBBPA, DMBPA or TMBPA (0.01-100 nM) and examined for centrosome numbers per cell (Figs 1 and 2). These concentrations are at environmentally relevant levels detected in adults and children (Zhou et al. 2014). Untreated cells that serve as controls showed the expected normal centrosome profile, in which most of the cells (>90\%) contain either one or two centrosomes. The cell lines treated with BPA, BPS, TBBPA and DMBPA have a significant increase (two- to six-fold) in the number of cells with three or more centrosomes (Figs 1 and 2) at either 0.01 or $0.1 \mathrm{nM}$ concentrations.
Also, the dose-response is found to be non-monotonic, as is commonly reported for the action of xenoestrogens and endocrine disruptors (Vandenberg et al. 2012, Vandenberg 2014). Moreover, CA is also observed in LNCaP cells in response to BPF and BPAF albeit at higher concentrations (100 and $10 \mathrm{nM}$, respectively), but not in C4-2 cells. Both cell lines were insensitive to treatment with TMBPA, implying that TMBPA does not affect the centrosome cycle. In summary, BPA, BPS, DMBPA and TBBPA, in descending order, exert the strongest effects on $\mathrm{CA}$ in a non-linear manner for both the AD and AI PCa cell lines.

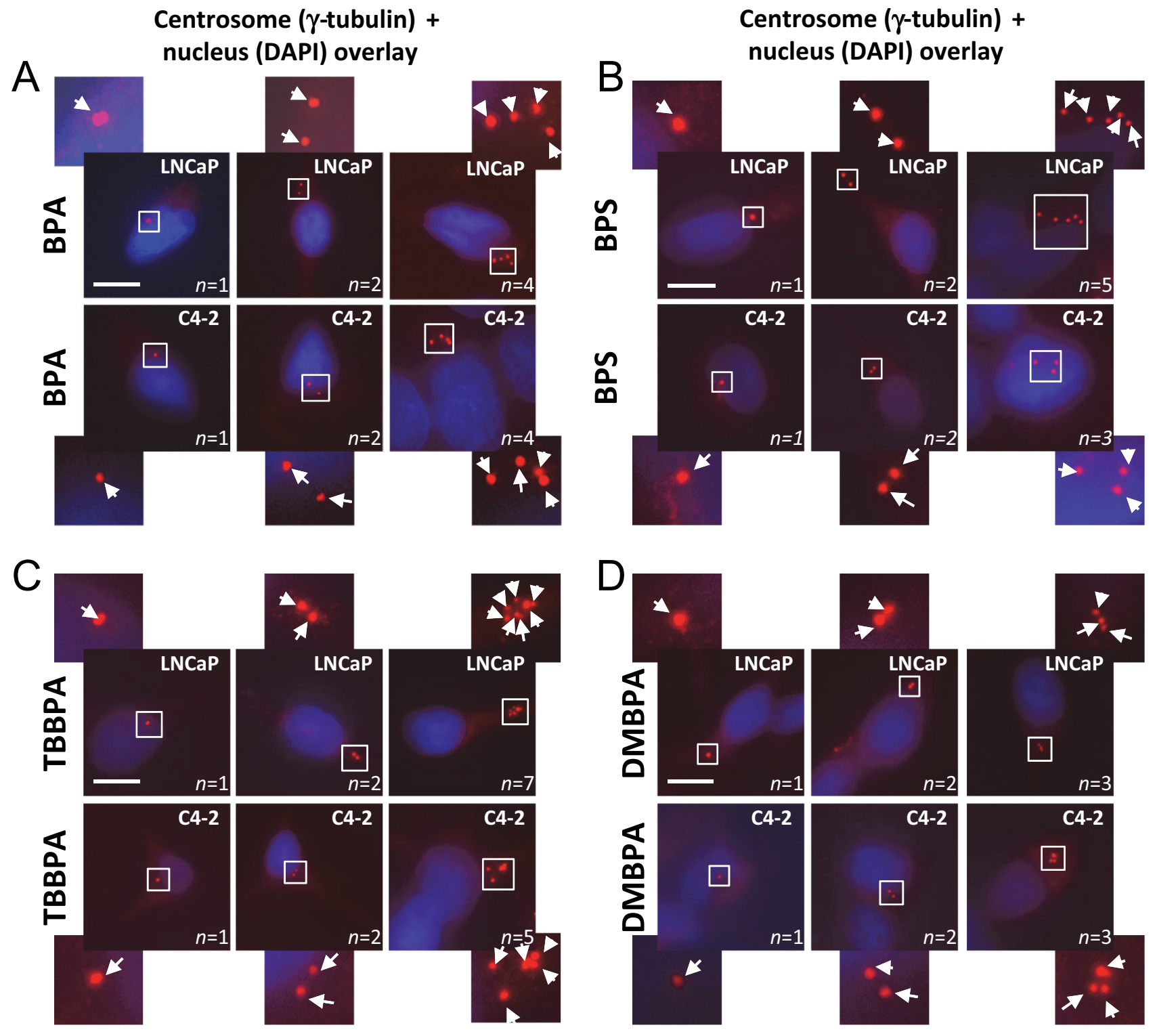

Figure 2

Representative staining showing cells with one, two and $>2$ centrosomes. LNCaP and C4-2 PCa cells were treated with (A) BPA, (B) BPS, (C) TBBPA and (D) DMBPA as indicated. Cells were fixed and immunostained with rabbit anti- $\gamma$-tubulin (red). DNA was stained using DAPI (blue). Arrows point to centrosomes ( $n$ =number of centrosomes). Pericentrin staining gave similar results. Scale bar, $20 \mu \mathrm{m}$. Area in square is magnified and offset to the main panel. 


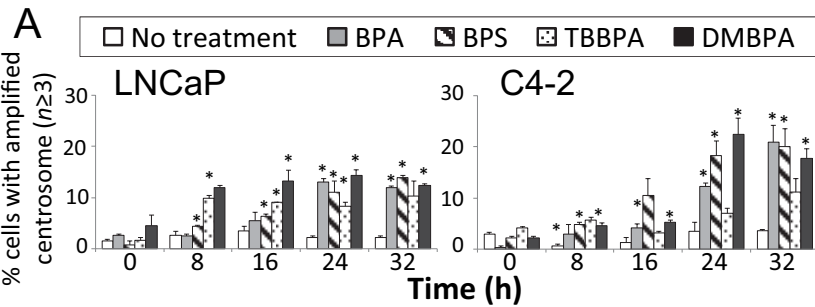

D Centrosome (Y-tubulin) + nucleus (DAPI)

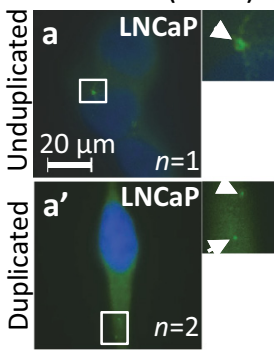

NPM + nucleus (DAPI)
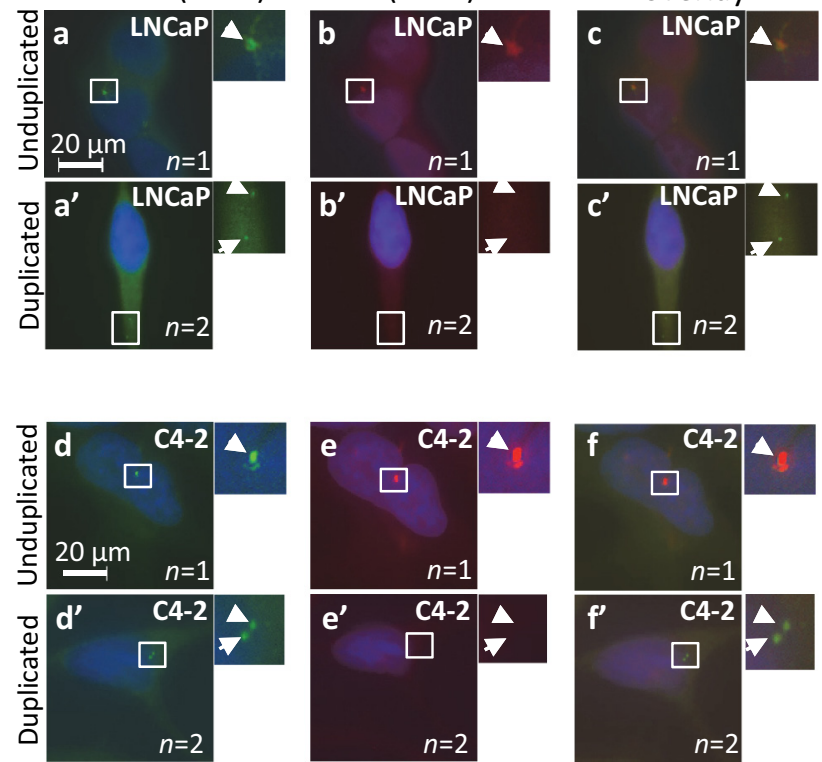

LNCaP Time (h)

Centrosome + $\mathrm{NPM}+$ nucleus overlay
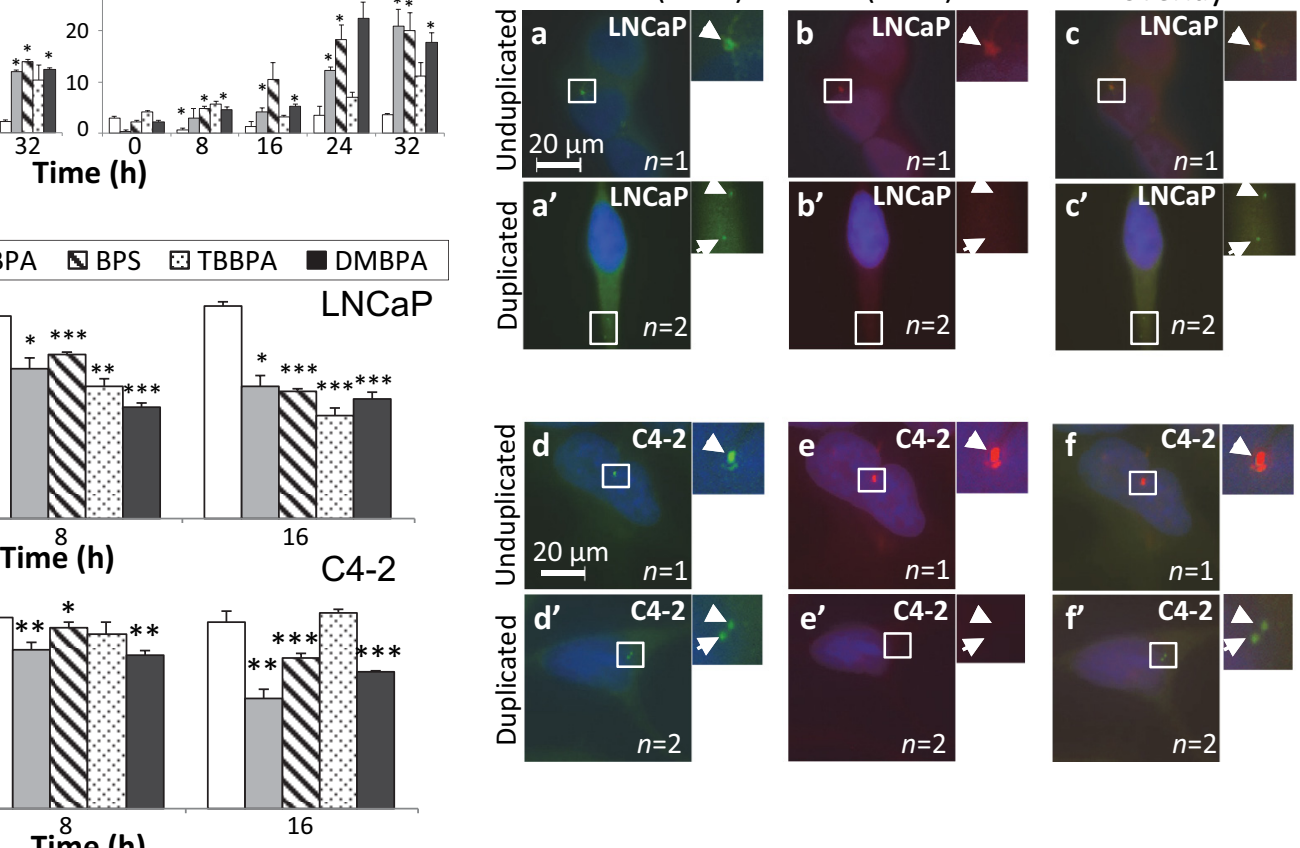

16

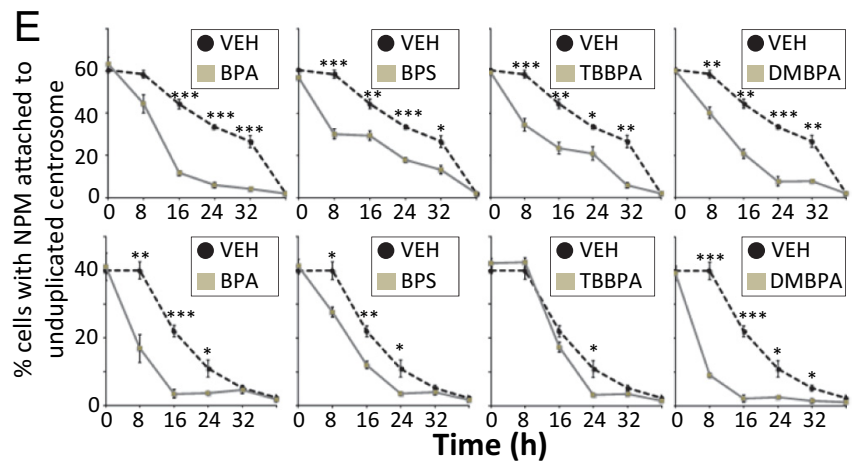

C4-2

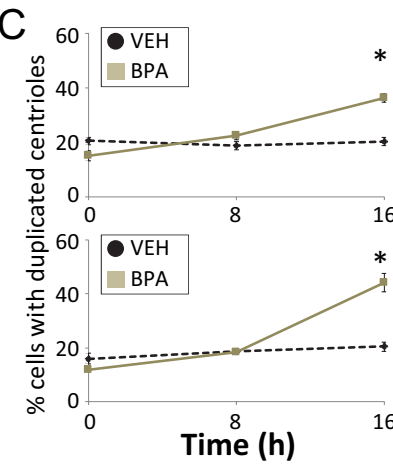

F

$\square$ No treatment $\square$ BPA

LNCaP
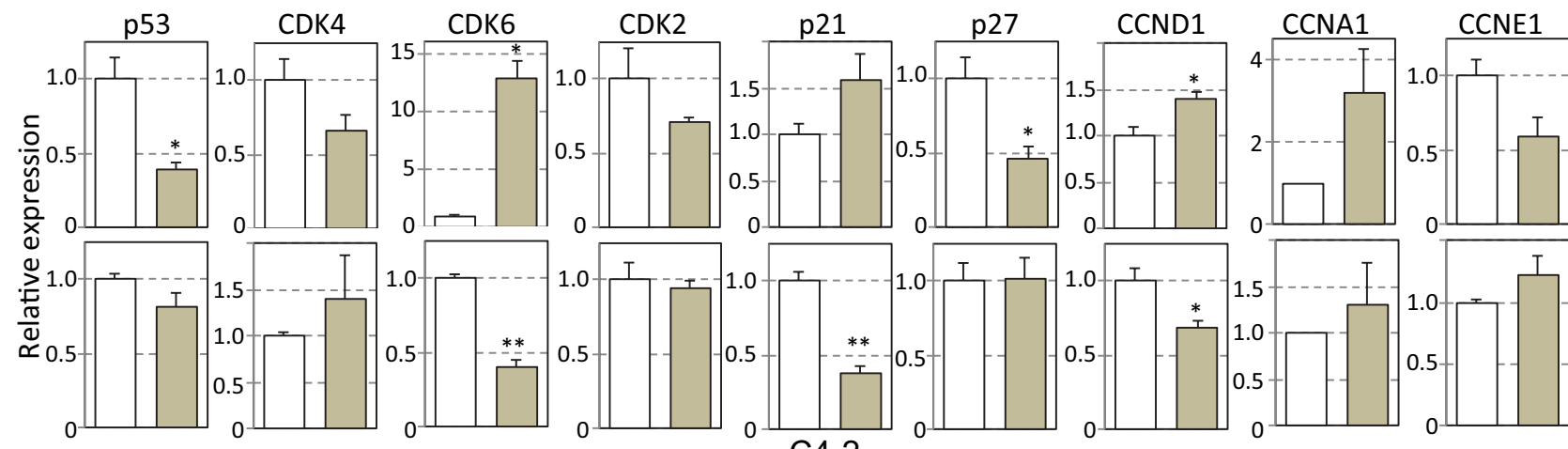

Figure 3

BPA promotes the initiation of centrosome duplication at an earlier time-point during G1 phase: LNCaP and C4-2 cells were serum starved in the presence of $0.5 \%$ CSS, media changed to $20 \%$ CSS \pm BPA, BPS, TBBPA and DMBPA, and cells fixed at the time-points indicated in graph. 


\section{Potential mechanism of CA dysregulation is related to an earlier timing of initiation of centrosome duplication}

We next determined the temporal pattern of centrosome amplification with the relevant BPA analogues. Cells were serum starved for $48 \mathrm{~h}$. Cells were then serum-stimulated and at every $8 \mathrm{~h}$ for a period of $40 \mathrm{~h}$, the number of amplified centrosomes per cell was scored. We found that the number of amplified centrosomes increased with time such that at $32 \mathrm{~h},>10 \%$ cells had amplified centrosomes (Fig. 3A). To maintain tight regulation of centrosome duplication, there are mechanisms in place to (1) inhibit the re-duplication of centrosomes in G1-phase of the cell cycle once centrosome duplication is initiated and (2) inhibit re-duplication of centrosomes in S-phase. First, we arrested cells in S-phase using DNA synthesis inhibitor aphidicolin, in the presence and absence of the various BPA analogues, but did not observe any significant centrosome number defects compared to vehicle control. This indicated that the observed CA is not due to defects in inhibition of centrosome re-duplication during S-phase. Next, to determine whether the timing for centrosome duplication is disrupted, we examined whether cells duplicated their centrosomes earlier in G1-phase, in the presence of BPA and its analogues. In vehicle control cells, less than $10 \%$ of centrosomes start duplicating at the 16-h time-point, in both LNCaP and C4-2 cells (Fig. 3B, white bar). However, in the presence of BPA and its analogues at the 8- and 16-h time-point, a $15-30 \%$ decrease in the number of unduplicated centrosomes (and a corresponding increase in the number of duplicated centrosomes) is observed indicating that centrosomes duplicated at an earlier time-point in the cell cycle in the presence of BPA. Each centrosome consists of a pair of centrioles and surrounding pericentriolar matrix. Immunostaining of centrin was performed to delineate whether PCa cells exposed to BPA were undergoing centriole duplication or separation. The percent cells undergoing centriole separation did not significantly change with time for both cell lines. At the 16-h time-point, on BPA treatment, $20-25 \%$ of the centrin spots increased from 2 ( 1 centrosome) to 3 or 4 ( 2 centrosomes) for both LNCaP and C4-2 cells, indicating that centriole duplication has occurred and not centriole separation (Fig. 3C).

To obtain a better understanding of the mechanism responsible for the earlier initiation of centrosome duplication, we examined for nucleophosmin (NPM) expression on single non-duplicated centrosomes. NPM localizes between the paired centrioles, and loss of NPM from the non-duplicated centrosome signals the first step in centrosome duplication. Cells were serum starved for $48 \mathrm{~h}$, and then stimulated with serum. At various time-points (Fig. 3D and E), cells were stained for NPM and centrosomes and examined for localization of NPM on unduplicated centrosomes. We found that in the presence of BPA, BPS, TBBPA and DMBPA, NPM was released from the single (non-duplicated) centrosome at an earlier time-point than that in control untreated cells. That is, for example, at the 16-h time-point, in the untreated cells, 42\% (LNCaP, Fig. 3E) and 22\% (C4-2, Fig. 3E) of cells have NPM on single centrosomes, versus 10\% (LNCaP, Fig. 3E) and 4\% (C4-2, Fig. 3E) in BPA-treated cells. Moreover, in the TBBPA-treated cells, we see earlier release of NPM in LNCaP cells, but not in C4-2 cells, similar to the CA profile (Fig. 1A and B, TBBPA). An 5-ethynyl-2'-deoxyuridine (EdU, Invitrogen) incorporation assay did not indicate a significant difference in cell proliferation between cells treated with vehicle or BPA, after release from serum starvation. Moreover, the total NPM protein levels in the BPAtreated cells did not change on 24-h treatment. Our data thus indicate that there is dysregulation in the timing of initiation of centrosome duplication and an earlier release of NPM from centrioles in cells treated with BPA and the respective analogues.

We then looked at the expression of G1-phase genes that are involved in the process of initiation of centrosome duplication. We found that expression of CDK2, CDK4, cyclin E1 and cyclin A2 did not change significantly in long-term BPA-treated cells (LNCaP/BPA and C4-2/BPA, Fig. 3F). p27kip1 and p53

At each time-point, cells were scored for centriole and centrosome numbers in LNCaP and C4-2 cell lines. (A) Scoring of number of cells with amplified centrosomes. (B) Scoring of number of cells with single centrosome. (C) Scoring of number of cells with duplicated centrioles. Around 5-10\% of cells had separated centrioles at 0, 8 and 16-h time-points. (D) Representative staining showing cells with NPM on single centrosomes. Unduplicated (a-c, g-i) and duplicated (d-f, j-l) LNCaP (a-f) and C4-2 (g-l) cells were immunostained for gamma-tubulin (green, a, d, g, j), NPM (red, b, e, h, k) and DAPI (blue). DAPI images (blue) were merged with gamma-tubulin (green) and NPM (red). Arrows indicate the positions of the centrosome ( $n=$ number of centrosomes). Scale bar, $20 \mu \mathrm{m}$. (E) Cells were scored for the presence or absence of NPM on non-duplicated centrosomes at various time-points in LNCaP and C4-2 cell lines. (F) Relative expression as determined by qRT-PCR for p53, CDK4, CDK6, CDK2, p21 Waf1, p27kip1, Cyclin D1 (CCND1), Cyclin A2 (CCNA2) and Cyclin E1 (CCNE1) in LNCaP (upper panel) and C4-2 (lower panel) cells in the absence (white bar) and presence (gray bar) of BPA. For the previously mentioned experiments, significance was determined using the Student's $t$-test compared to $0 \mathrm{~h}$ or vehicle treatment (*P<0.05, $* * P \leq 0.01, * * * P \leq 0.001)$. Bars, s.E. of three independent experiments. 
LNCaP

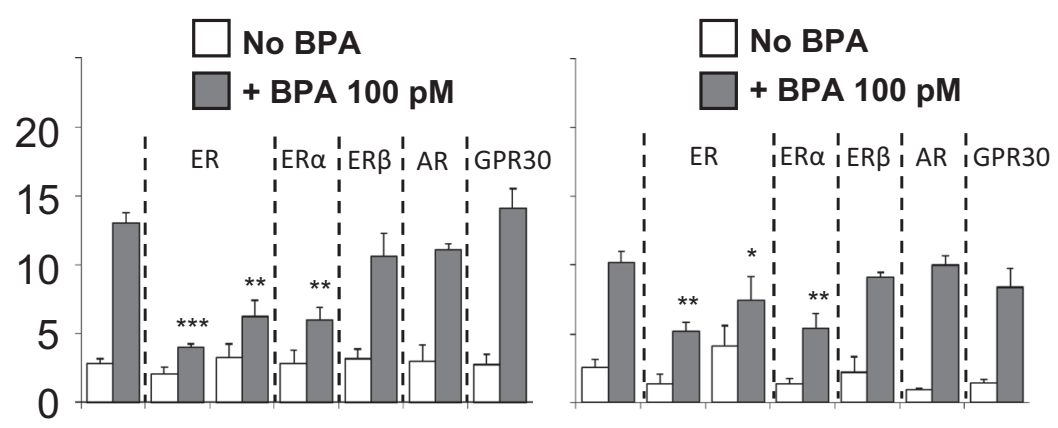

\section{C4-2}
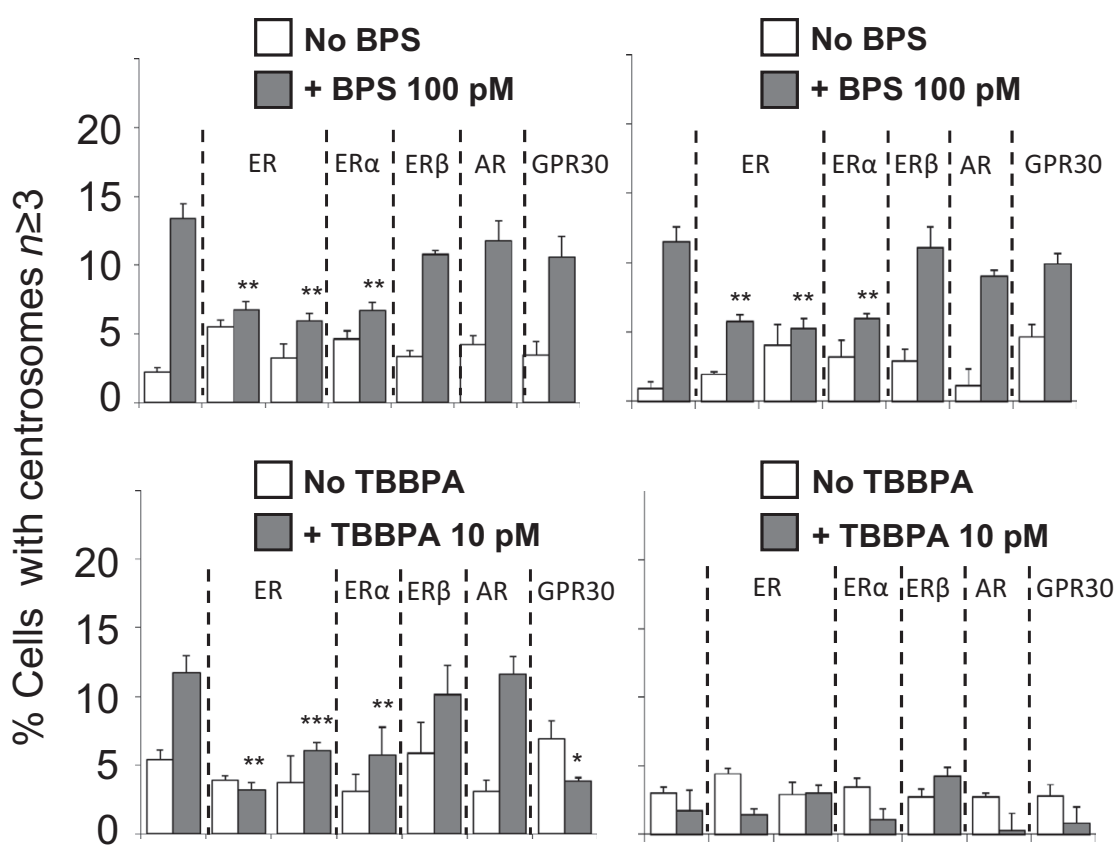

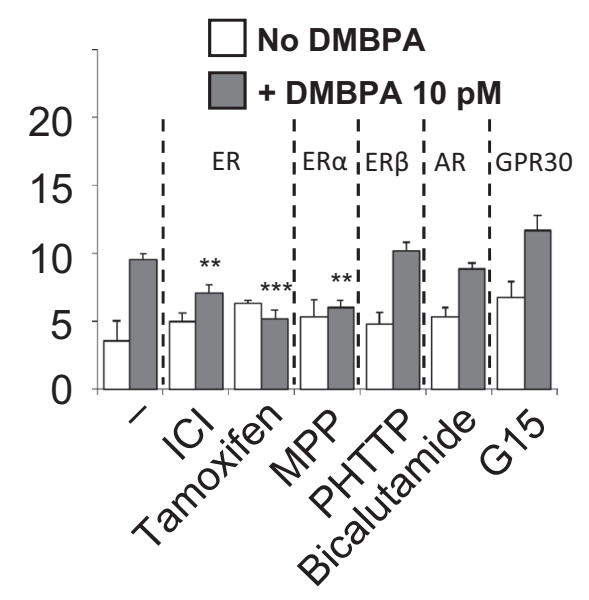

expression was decreased (0.5- and 0.4-fold, respectively) and CDK6 (13-fold) and cyclin D1 (1.4 fold) increased in LNCaP/BPA cells compared to that in vehicle control (Fig. 3F). This implies that $p 53, p 27^{k i p 1}, C D K 6$ and cyclin $D 1$ could be the main drivers for initiation of centrosome
○ 2017 Society for Endocrinology Printed in Great Britain

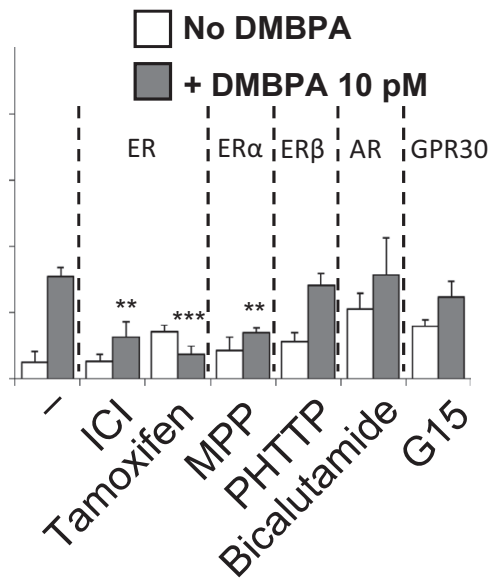

Figure 4

CA in the presence of BPA and its analogues may involve ER-alpha (ESR1). LNCaP and C4-2 Cells were treated with inhibitors for ER (ICl), ESR1 (MPP), ESR2 (PHTPP), AR (bicalutamide) and GPR30 (G15) for $72 \mathrm{~h}$ in the presence and absence of BPA and its analogues as indicated. Cells were fixed and scored for number of cells with centrosome numbers $\geq 3$. Significance was calculated relative to no inhibitor group. $* P<0.05, * * P<0.005, * * * P<0.001$. Bars, s.E. of the three independent experiments. cycle in AD LNCaP/BPA cells. For the AI C4-2/BPA cells, there was decreased expression of $p 21^{\text {Waf1 }}$ (0.4-fold). Hence, in the BPA-treated $\mathrm{AD}$ and $\mathrm{AI}$ cells, the expression of different CDK inhibitors ( $p 27^{\mathrm{kip} 1}$ and $p 21^{\text {Waf } 1}$, respectively) is downregulated. These results indicate that the G1-phase 
A

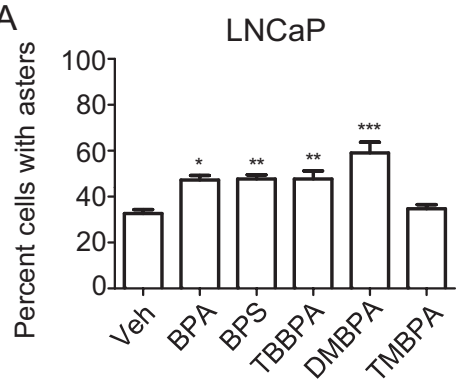

$A^{\prime}$
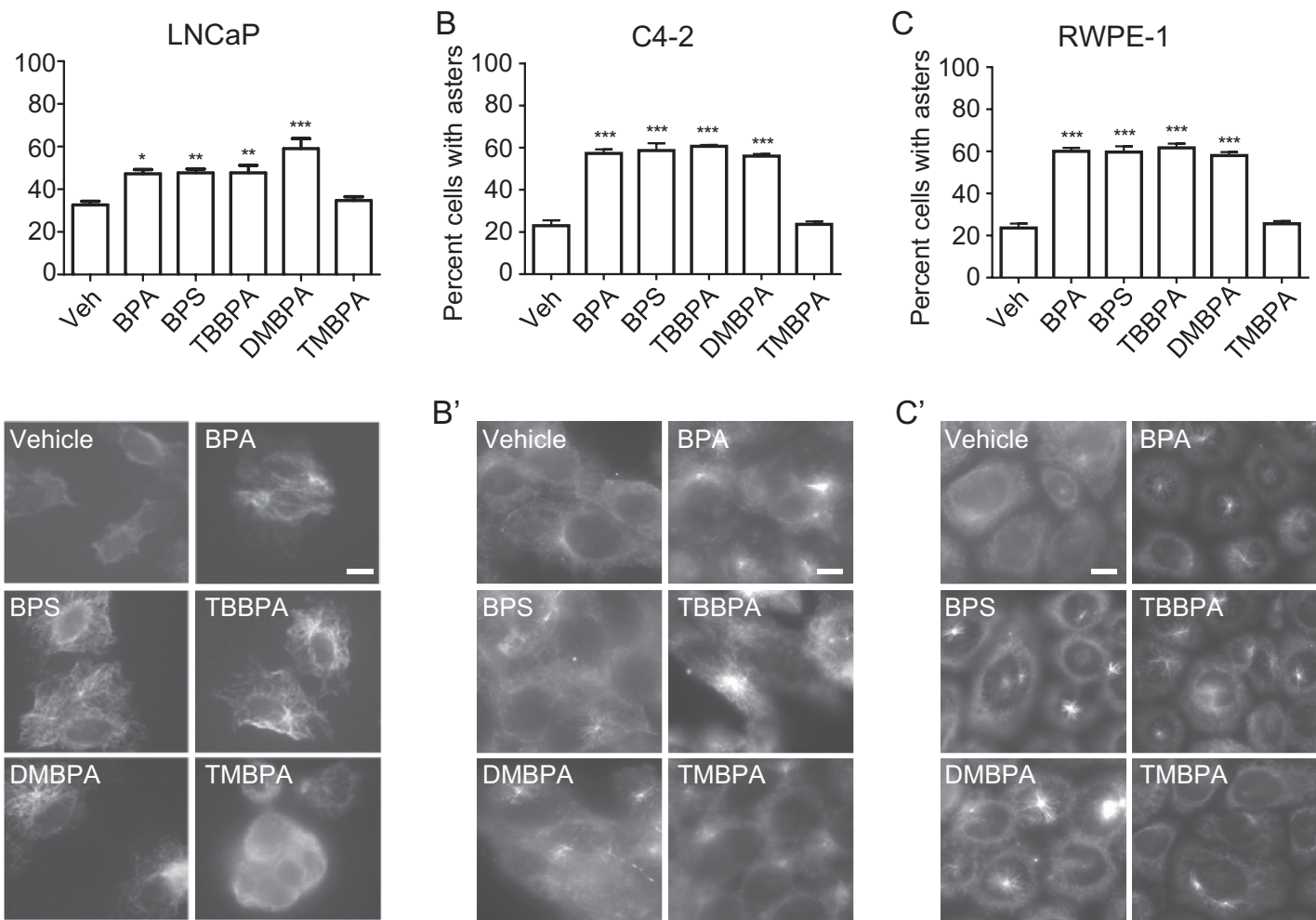

$C^{\prime}$
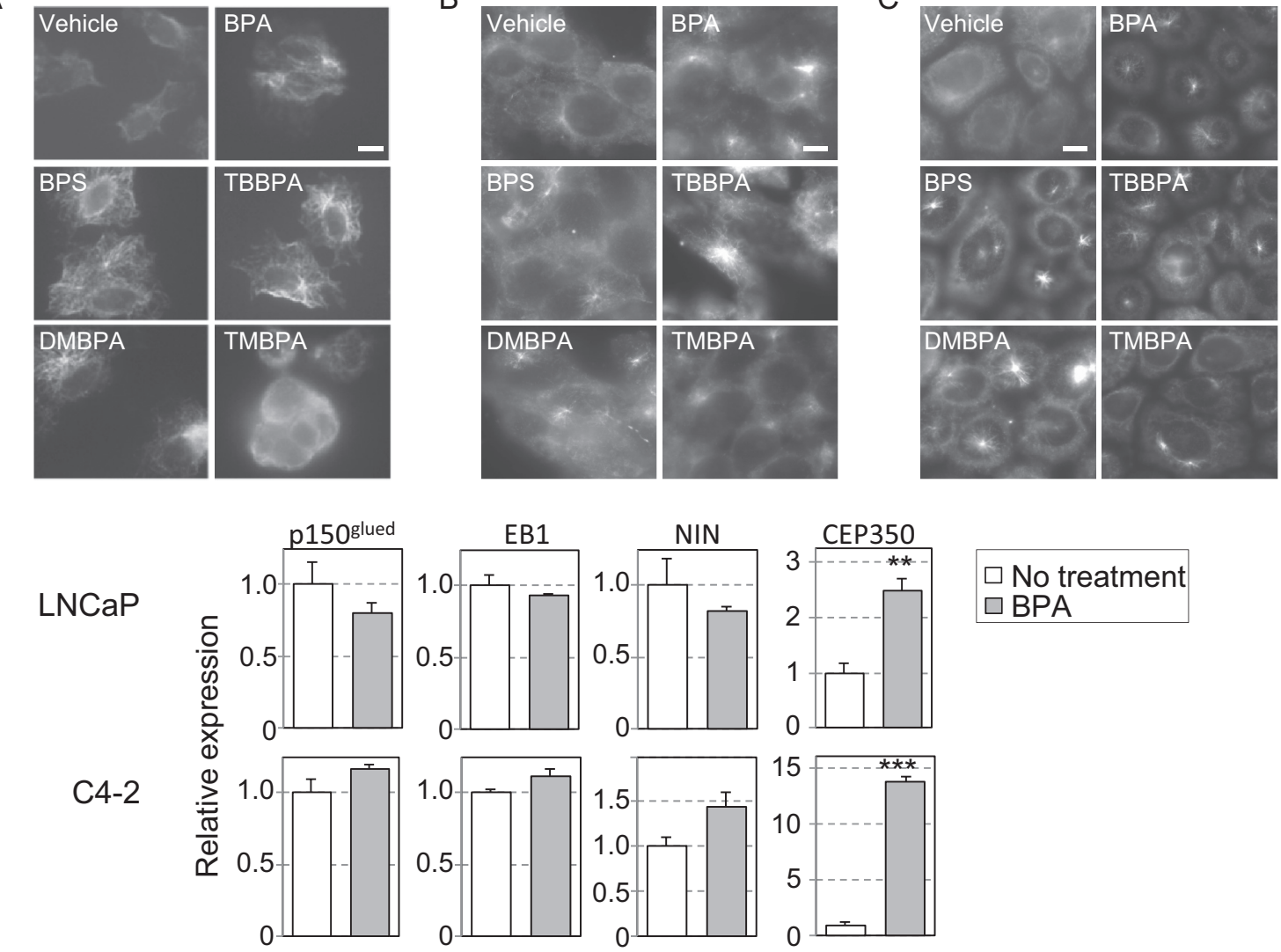

$\square$ No treatment

$\square$ BPA

Figure $\mathbf{5}$

BPA, BPS, DMBPA and TBBPA enhancement of centrosomal MT-aster formation is accompanied with increased expression of CEP350. LNCaP (A), C4-2 (B) cells and (C) RWPE1 cells were treated with vehicle (veh), BPA, BPS, TBBPA, DMBPA and TMBPA as indicated. Cells were fixed and immunostained for centrosomes (anti-gamma-tubulin) and MTs (anti-alpha-tubulin). Centrosomal aster formation was counted as positive if centrosomes nucleated greater than 15 asters. (A, B, C) The percent cells positive for MT-asters were scored ( $\left.A^{\prime}, B^{\prime}, C^{\prime}\right)$ Representative staining showing MT-aster formation. (D) Relative expression as determined by qRT-PCR for p150glued, EB1, Ninein and CEP350 in LNCaP and C4-2 cells in the absence (white bar) and presence (gray bar) of BPA. For above experiments, significance was determined using a Student's $t$-test compared to vehicle treatment (*P<0.05, $* \star P \leq 0.01, * * \star P \leq 0.001)$.

Bars, S.E.M. of the three independent experiments.

CDKs (CDK4, CDK6 and CDK2) are affected by BPA, albeit by downregulating the expression of different CDK inhibitors.

\section{CA in the presence of BPA and some of its analogues is dependent on estrogen receptor alpha (ESR1)}

The goal of this experiment was to identify which and whether estrogen and androgen receptors mediate CA induced by exposure to BPA and its analogues. Five inhibitors were used: (a) Fulvestrant (ICI) an antagonist for ESR1 and ESR2 (Fitts et al. 2011), which degrades receptor proteins; (b) MPP, an antagonist for ESR1; (c) PHTPP, an antagonist for ESR2; (d) bicalutamide an antagonist for AR; and (e) G15, an antagonist for GPER1. Cells were treated with $0.1 \mathrm{nM}$ BPA, BPS and DMBPA or $0.01 \mathrm{nM}$ TBBPA in the presence and absence 
of inhibitors for the respective nuclear receptors (Fig. 4). Treatment of cells with BPA and its analogues in the presence of ICI, but not bicalutamide or G15, inhibited CA, suggesting that ESR1 or ESR2 is involved in this process. Furthermore, treatment of cells with BPA and its analogues along with MPP (ESR1 antagonist), and not with PHTPP, inhibited CA suggesting that the $\mathrm{CA}$ induced by BPA and its analogues is dependent on ESR1.

\section{Low-dose BPA, BPS, TBBPA and DMBPA enhance MT-aster formation, a measure of tumor progression}

Centrosomes are the MT-organizing center in cells. During interphase, changes in MT dynamics usually associate with loss of tumor architecture, increased motility and invasiveness, decreased cell adherence and thus, tumor aggressiveness (Lingle et al. 2002). To perform MT-aster formation assay, LNCaP, C4-2 and RWPE1 cells were exposed to BPA and its analogues for 3 days. Cells were treated with nocodazole to depolymerize the interphase MTs; nocodazole was then removed, and cells were incubated in fresh warm medium for MT regrowth. The centrosomes' ability to nucleate, anchor and elongate MTs was determined by co-immunostaining for centrosomes (anti- $\gamma$-tubulin) and MTs (anti-alpha-tubulin). The aster-forming activity of centrosomes was assessed according to the previously established protocol (Tarapore et al. 2012). 20-30\% of untreated LNCaP, C4-2 and RWPE-1 cells (Fig. 5A, B and C, respectively) showed MT-aster formation, whereas $\sim 48-60 \%$ cells treated with BPA, BPS, TBBPA and DMBPA showed the presence of MT-asters (Fig. 5A, A', B, B', C and $\mathrm{C}^{\prime}$ ). Our data thus indicate that BPA and some of its analogues enhance MT-aster formation.

A number of proteins involved in MT anchorage and elongation at the centrosome have been identified. These include p150glued, EB1, Ninein (NIN) and CEP350 (Mogensen et al. 2000, Yan et al. 2006, Azimzadeh \& Bornens 2007). As BPA, BPS, TMBPA and DMBPA had similar effects on MT-aster formation, we used the prototype bisphenol BPA for further analyses. We examined the expression of these genes in LNCaP and C4-2 cells. Although no significant changes were observed in the expression of p150glued, EB1 and NIN, CEP350 was found to be upregulated 2.5- and 13-fold in LNCaP and C4-2 cells treated with BPA, respectively (Fig. 5D).
Table 2 Anchorage-independent growth (\%average \pm S.E. of colonies).

\begin{tabular}{|c|c|c|}
\hline & LNCaP & C4-2 \\
\hline Vehicle & 0.64 & 2.00 \\
\hline BPA & $0.46 \pm 0.14$ & $5.30 \pm 0.79 * *$ \\
\hline BPS & $0.69 \pm 0.34$ & $2.94 \pm 0.4$ \\
\hline TBBPA & $0.93 \pm 0.5$ & $2.22 \pm 0.62$ \\
\hline DMBPA & $1.90 \pm 0.25 * *$ & $3.66 \pm 0.36$ ** \\
\hline TMBPA & 0.66 & 1.92 \\
\hline
\end{tabular}

\section{Chronic exposure to DMBPA promotes anchorage-independent growth}

Cancer progression can also be measured in vitro by anchorage-independent growth (Mori et al. 2009). The ability of chronic low-dose BPA, BPS, TBBPA and DMBPA exposure to promote anchorage-independent growth of LNCaP and C4-2 cells was assessed by a soft agar colony formation assay. The cells were grown in medium with or without BPA or its analogues for 10-14 passages before they were seeded on soft agar in the presence of same analogues. As previously observed (Tarapore et al. 2014), only the C4-2 cells showed significant increase in number of colonies on treatment with BPA (Table 2). The percent efficiency of colony formation (mean \pm S.E.) increased to $5.3 \pm 0.8 \%$ with BPA treatment compared with $2.0 \%$ in unexposed controls $(P<0.006)$. However, on chronic treatment with DMBPA, both LNCaP and C4-2 cells showed an increase in efficiency of colony formation of $~ 2.4$ - and 1.83 -fold compared with unexposed controls $(P<0.006)$.

\section{Discussion}

In this study, we examined the effects of $6 \mathrm{BPA}$ analogues along with BPA at nanomolar range on CA to ascertain their endocrine-disrupting effects with reference to BPA. We found that exposure to BPS, DMBPA and TBBPA resulted in a non-monotonic increase in number of cells with $\mathrm{CA}$, maybe primarily via ESR1 signaling. In addition to promoting CA, exposure to BPS, TBBPA and DMBPA also resulted in increased stability of MT-asters at centrosomes. Finally, treatment of cells with DMBPA but not with the other analogues resulted in an enhancement of anchorage-independent growth, similar to BPA exposure. Thus, DMBPA appears to be the most potent analogue when compared to BPA in its action to promote cancer-related features.

BPA has now been in commercial use for 57 years, and numerous health effects including increasing

Published by Bioscientifica Ltd. 
cancer risk have been reported to be associated with its usage (Keri et al. 2007, Ho et al. 2012, Rogers et al. 2013, Zawatski \& Lee 2013). We and others have demonstrated the involvement of BPA in increasing PCa risk through early life reprograming (Ho et al. 2006, Tang et al. 2012, Prins et al. 2014) as well as chronic life exposure (Lam et al. 2015). These observations are in agreement with a limited amount of human evidence including a small retrospective study, which found BPA levels in the urine of PCa patients were higher than those in nonPCa patients (Tarapore et al. 2014). Multiple mechanisms have been proposed for BPA action, including epigenetic reprogramming of gene expression (Ho et al. 2006, Tang et al. 2012), increased expansion of stem-like progenitor cells in the prostate (Prins et al. 2014), altering biosynthesis pathways such as the SNORDs (Ho et al. 2015), disrupting the MTs (Pfeiffer et al. 1997, Ochi 1999), causing adduct formation and DNA damage (Fic et al. 2013) and increasing CA (Tarapore et al. 2014). Centrosomes are the MT-organizing center in cells, and by this process regulate cell orientation, polarity and migration. They are involved in mitosis as well as organelle transport. Increase in centrosomal MT anchoring and regrowth is a marker for tumor cell progression, and changes in MT dynamics usually associate with loss of tumor architecture and hence promote loss of cell adhesion, tumor motility and invasiveness (Lingle et al. 2002). Growth on soft agar is indicative of a transformed phenotype. We found that although BPA, BPS, TBBPA and DMBPA increased CA and MT dynamics, only BPA and DMBPA significantly transformed the cells. Going forward, investigating whether DMBPA increases risk to $\mathrm{PCa}$ is of paramount importance. Whether BPA and DMBPA are allowing for expansion of a stem cell population or allowing the establishment of a more metastatic phenotype remains to be determined and is an area of on-going research.

As we replace BPA with other BPA analogues in plastic containers, bottles, receipts and toys, it is important to note that the health effects of these analogues are just emerging. For example, BPA analogues such as BPS, BPF and TBBPA were found to disrupt multiple nuclear receptors and may therefore interfere with the endocrine system (Molina-Molina et al. 2013). Moreover, exposure of zebrafish to BPS during their development impaired their subsequent reproduction potential and hormonal balance when adult (Naderi et al. 2014). BPS also disrupted membrane-initiated estradiol-induced cell signaling, leading to altered cell proliferation, cell death and prolactin release (Vinas \& Watson 2013) in a rat pituitary cell line. Rapid exposure to low-dose BPS showed proarrhythmic impact on ex vivo female rat hearts and myocytes (Gao et al. 2015). For the first time in this study, we show that like BPA, BPS, TBBPA and DMBPA affect CA, probably via ESR1.

In the context of mechanism, we found that centrosome duplication occurs at an earlier time-point in the presence of BPA, BPS, DMBPA and TBBPA. In AD (LNCaP) and AI (C4-2) cells, the same group of CDKs (CDK4, CDK6 and CDK2) is affected by BPA, albeit through downregulating the expression of different $\mathrm{CDK}$ inhibitors $p 27^{k i p 1}$ and $p 21^{\text {Waf1 }}$, respectively (Fig. 6). We show that in the presence of BPA, the expression of CDK6 and cyclin D1 increases and that of $p 21^{\text {Waf } 1}$ or $p 27^{k i p 1}$ decreases. Previous studies show that CDK4, CDK6 and CDK2 phosphorylate NPM at Thr199 initiating the separation of centrosomes (Hinchcliffe et al. 1999, Cuomo et al. 2008, Adon et al. 2010), as the first step in centrosome duplication. We and others have shown that centrosomes can duplicate during prolonged exposure to G1-phase, albeit much slower than when arrested at G1/S boundary or S-phase (Hinchcliffe et al. 1999, Tarapore et al. 2002). We can thus speculate that an earlier release of NPM would allow a second round of centrosome duplication to occur later during G1-phase or early S-phase, in BPA-treated cells. Timing of NPM release at non-duplicated centrosomes thus appears to be the key step disrupted in cells treated with BPA and some of its analogues. This does not appear to be loss of regulation of centrosome re-duplication during S-phase as arresting cells using DNA synthesis inhibitors did not result in significant differences in centrosome amplification of BPA and its analogues compared to vehicle control. This suggests that controls are still in place to inhibit re-duplication of centrosomes during S-phase.

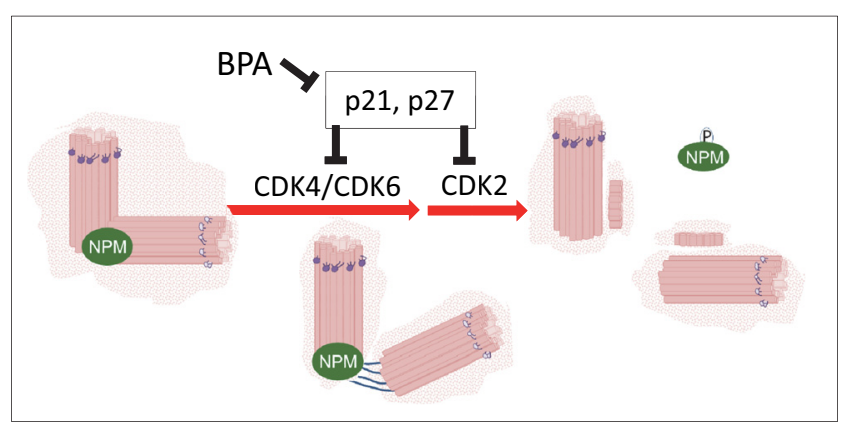

Figure 6

NPM in regulation of the initiation of centrosome duplication. Centrosome-bound NPM dissociates from centrosomes upon phosphorylation by CDK2, CDK4 or CDK6, which triggers the initiation of centriole duplication. $p 21$ Waf1 and $p 27 k i p 1$ inhibit CDK activation, and thus, initiation of centrosome replication.

Published by Bioscientifica Ltd. 
By nucleating and anchoring MTs, the centrosome influences MT-directed processes including shape, polarity, organelle transport, adhesion, motility and division of cells. We found that CA was observed in only 10-15\% cells in a population on exposure to BPA analogues. However, 40\% more cells showed the formation of MT-asters compared to vehicle control. Hence, we are probably observing the effects of BPA and its analogues on a function of the centrosome distinct from the CA phenotype. Involved in the process of MT anchoring at the centrosomes, are the proteins NIN, p150 Glued, EB1 and CAP350 (Yan et al. 2006, Pihan 2013). We found that expression of CEP350 is upregulated in BPA-treated LNCaP and C4-2 cells compared to untreated controls. Previous studies have suggested that CAP350, EB1 and FOP (FGFR1 oncogene partner) form a centrosomal complex required for MT anchoring and elongation. Depletion of CAP350, $F O P$ or $E B 1$ by siRNA caused loss of MT anchoring and profound disorganization of the MT network, whereas the overexpression of CAP350 promoted an increase in the stability of the MT network (Hoppeler-Lebel et al. 2007). Our results on the MT-aster assay further support this result and suggest that overexpression of CAP350 could be promoting MT anchoring and stability. Intriguingly, in addition to its function in MT anchoring, CEP350 has also been shown to be involved in regulating procentriole stability and growth/assembly (Le 2008). The implications of overexpression of CEP350 on exposure to BPA and its analogues thus warrant further investigation.

In conclusion, we have found that some BPA analogues (BPS, TBBPA and DMBPA) are more potent than others (BPF, BPAF and TMBPA) for CA, an indicator for cancer severity. BPA affects the expression of two different G1-phase CDK inhibitors, which target the same signaling pathway, resulting in the release of NPM from centrosomes during G1-phase at an earlier timepoint. BPA, BPS, TBBPA and DMBPA all equally affect MT anchorage and growth, a proxy for cell aggressiveness. Finally, DMBPA is most comparable to BPA in that it can affect anchorage-independent growth of cells, a measurement of cell transformation. Our results therefore indicate that it is increasingly important to examine the actions of these analogues before their use becomes too widespread as substitutes for BPA in consumer products.

\section{Declaration of interest}

The authors declare that there is no conflict of interest that could be perceived as prejudicing the impartiality of the research reported.

\section{Funding}

This study was supported in part by grants from the National Institutes of Health (P30ES006096 (SMH), U01ES019480 (SMH) and U01ES019480 $(\mathrm{SMH}))$; the Department of Defense (W81XWH-15-1-0353 (PT)); National Health and Medical Research Council (GNT1070112 (ST)) and the United States Department of Veterans Affairs (I01BX000675 (SMH)).

\section{Acknowledgments}

The authors would like to thank Kevin Burridge for technical assistance.

\section{References}

Adon AM, Zeng X, Harrison MK, Sannem S, Kiyokawa H, Kaldis P \& Saavedra HI 2010 Cdk2 and Cdk4 regulate the centrosome cycle and are critical mediators of centrosome amplification in p53-null cells. Molecular and Cellular Biology 30 694-710. (doi:10.1128/ MCB.00253-09)

Azimzadeh J \& Bornens M 2007 Structure and duplication of the centrosome. Journal of Cell Science 120 2139-2142. (doi:10.1242/ jcs.005231)

Becerra V \& Odermatt J 2012 Detection and quantification of traces of bisphenol A and bisphenol S in paper samples using analytical pyrolysis-GC/MS. Analyst 137 2250-2259. (doi:10.1039/c2an15961a)

Cariou R, Antignac JP, Zalko D, Berrebi A, Cravedi JP, Maume D, Marchand P, Monteau F, Riu A, Andre F, et al. 2008 Exposure assessment of French women and their newborns to tetrabromobisphenol-A: occurrence measurements in maternal adipose tissue, serum, breast milk and cord serum. Chemosphere $\mathbf{7 3}$ 1036-1041. (doi:10.1016/j.chemosphere.2008.07.084)

Cuomo ME, Knebel A, Morrice N, Paterson H, Cohen P \& Mittnacht S 2008 p53-Driven apoptosis limits centrosome amplification and genomic instability downstream of NPM1 phosphorylation. Nature Cell Biology 10 723-730. (doi:10.1038/ncb1735)

Danzl E, Sei K, Soda S, Ike M \& Fujita M 2009 Biodegradation of bisphenol A, bisphenol $\mathrm{F}$ and bisphenol $\mathrm{S}$ in seawater. International Journal of Environmental Research and Public Health 6 1472-1484. (doi:10.3390/ijerph6041472)

Fernandez MF, Kiviranta H, Molina-Molina JM, Laine O, Lopez-Espinosa MJ, Vartiainen T \& Olea N 2008 Polychlorinated biphenyls (PCBs) and hydroxy-PCBs in adipose tissue of women in Southeast Spain. Chemosphere 71 1196-1205. (doi:10.1016/j. chemosphere.2007.09.064)

Fic A, Zegura B, Sollner DM, Filipic M \& Peterlin ML 2013 Mutagenicity and DNA damage of bisphenol A and its structural analogues in HepG2 cells. Archives of Industrial Hygiene and Toxicology 64 3-14. (doi:10.2478/10004-1254-64-2013-2319)

Fitts JM, Klein RM \& Powers CA 2011 Tamoxifen regulation of bone growth and endocrine function in the ovariectomized rat: discrimination of responses involving estrogen receptor alpha/ estrogen receptor beta, $\mathrm{G}$ protein-coupled estrogen receptor, or estrogen-related receptor gamma using fulvestrant (ICI 182780). Journal of Pharmacology and Experimental Therapeutics 338 246-254. (doi:10.1124/jpet.110.173955)

Gallart-Ayala H, Moyano E \& Galceran MT 2011 Fast liquid chromatography-tandem mass spectrometry for the analysis of bisphenol A-diglycidyl ether, bisphenol F-diglycidyl ether and their derivatives in canned food and beverages. Journal of Chromatography A 1218 1603-1610. (doi:10.1016/j.chroma.2011.01.026)

Gao X, Ma J, Chen Y \& Wang HS 2015 Rapid responses and mechanism of action for low-dose bisphenol $\mathrm{S}$ on ex vivo rat hearts and isolated myocytes: evidence of female-specific proarrhythmic effects.
๑ 2017 Society for Endocrinology Printed in Great Britain
Published by Bioscientifica Ltd 
Environmental Health Perspectives 123 571-578. (doi:10.1289/ ehp.1408909)

Godinho SA \& Pellman D 2014 Causes and consequences of centrosome abnormalities in cancer. Philosophical Transactions of the Royal Society B: Biological Sciences 369 20130467. (doi:10.1098/rstb.2013.0467)

Hinchcliffe EH, Li C, Thompson EA, Maller JL \& Sluder G 1999 Requirement of Cdk2-cyclin E activity for repeated centrosome reproduction in Xenopus egg extracts. Science 283 851-854. (doi:10.1126/science.283.5403.851)

Ho SM, Tang WY, Belmonte de FJ \& Prins GS 2006 Developmental exposure to estradiol and bisphenol A increases susceptibility to prostate carcinogenesis and epigenetically regulates phosphodiesterase type 4 variant 4. Cancer Research 66 5624-5632. (doi:10.1158/0008-5472.CAN-06-0516)

Ho SM, Lee MT, Lam HM \& Leung YK 2011 Estrogens and prostate cancer: etiology, mediators, prevention, and management. Endocrinology and Metabolism Clinics of North America 40 591-614, ix. (doi:10.1016/j.ecl.2011.05.002)

Ho SM, Johnson A, Tarapore P, Janakiram V, Zhang X \& Leung YK 2012 Environmental epigenetics and its implication on disease risk and health outcomes. Institute for Laboratory Animal Research 53 289-305. (doi:10.1093/ilar.53.3-4.289)

Ho SM, Cheong A, Lam HM, Hu WY, Shi GB, Zhu X, Chen J, Zhang X, Medvedovic M, Leung Y-K, et al. 2015 Exposure of human prostaspheres to Bisphenol A epigenetically regulates SNORD family non-coding RNAs via histone modification. Endocrinology 156 3984-3995. (doi:10.1210/en.2015-1067)

Hoppeler-Lebel A, Celati C, Bellett G, Mogensen MM, Klein-Hitpass L, Bornens M \& Tassin A.-M. 2007 Centrosomal CAP350 protein stabilises microtubules associated with the Golgi complex. Journal of Cell Science 120 3299-3308. (doi:10.1242/jcs.013102)

Ike M, Chen MY, Danzl E, Sei K \& Fujita M 2006 Biodegradation of a variety of bisphenols under aerobic and anaerobic conditions. Water Science \& Technology 53 153-159. (doi:10.2166/ wst.2006.189)

Jimenez-Diaz I, Zafra-Gomez A, Ballesteros O, Navea N, Navalon A, Fernandez MF, Olea N \& Vílchez JL 2010 Determination of Bisphenol A and its chlorinated derivatives in placental tissue samples by liquid chromatography-tandem mass spectrometry. Journal of Chromatography B: Analytical Technologies in the Biomedical and Life Sciences 878 3363-3369. (doi:10.1016/j. jchromb.2010.10.021)

Johnson-Restrepo B, Adams DH \& Kannan K 2008 Tetrabromobisphenol A (TBBPA) and hexabromocyclododecanes (HBCDs) in tissues of humans, dolphins, and sharks from the United States. Chemosphere 70 1935-1944. (doi:10.1016/j.chemosphere.2007.10.002)

Keri RA, Ho SM, Hunt PA, Knudsen KE, Soto AM \& Prins GS 2007 An evaluation of evidence for the carcinogenic activity of bisphenol A. Reproductive Toxicology 24 240-252. (doi:10.1016/j. reprotox.2007.06.008)

Kitamura S, Kato T, Iida M, Jinno N, Suzuki T, Ohta S, Fujimoto N, Hanada H, Kashiwagi K \& Kashiwagi A 2005 Anti-thyroid hormonal activity of tetrabromobisphenol A, a flame retardant, and related compounds: Affinity to the mammalian thyroid hormone receptor, and effect on tadpole metamorphosis. Life Sciences 76 1589-1601. (doi:10.1016/j.lfs.2004.08.030)

Lam HM, Ho SM, Chen J, Medvedovic M \& Tam NN 2015 Bisphenol A disrupts HNF4alpha-regulated gene networks linking to prostate preneoplasia and immune disruption in Noble rats. Endocrinology 157 207-219. (doi:10.1210/en.2015-1363)

Le CM 2008 Role of CAP350 in centriolar tubule stability and centriole assembly. PLOS ONE 3 e3855. (doi:10.1371/journal. pone.0003855)

Liao C, Liu F, Alomirah H, Loi VD, Mohd MA, Moon HB, Nakata H \& Kannan K 2012a Bisphenol S in urine from the United States and seven Asian countries: occurrence and human exposures. http://erc.endocrinology-journals.org

DOI: 10.1530/ERC-16-0175
(C) 2017 Society for Endocrinology Printed in Great Britain
Environmental Science \& Technology 46 6860-6866. (doi:10.1021/ es301334j)

Liao C, Liu F \& Kannan K $2012 b$ Bisphenol s, a new bisphenol analogue, in paper products and currency bills and its association with bisphenol a residues. Environmental Science \& Technology 46 6515-6522. (doi:10.1021/es300876n)

Lingle WL, Barrett SL, Negron VC, D'Assoro AB, Boeneman K, Liu W, Whitehead CM, Reynolds C \& Salisbury JL 2002 Centrosome amplification drives chromosomal instability in breast tumor development. PNAS 99 1978-1983. (doi:10.1073/pnas.032479999)

Mazia D 1987 The chromosome cycle and the centrosome cycle in the mitotic cycle. International Review of Cytology 100 49-92. (doi:10.1016/s0074-7696(08)61698-8)

Mogensen MM, Malik A, Piel M, Bouckson-Castaing V \& Bornens M 2000 Microtubule minus-end anchorage at centrosomal and noncentrosomal sites: the role of ninein. Journal of Cell Science $\mathbf{1 1 3}$ 3013-3023.

Molina-Molina JM, Amaya E, Grimaldi M, Saenz JM, Real M, Fernandez MF, Balaguer P \& Olea N 2013 In vitro study on the agonistic and antagonistic activities of bisphenol-S and other bisphenol-A congeners and derivatives via nuclear receptors. Toxicology and Applied Pharmacology 272 127-136. (doi:10.1016/j. taap.2013.05.015)

Mori S, Chang JT, Andrechek ER, Matsumura N, Baba T, Yao G, Kim JW Gatza M, Murphy S \& Nevins JR 2009 Anchorage-independent cell growth signature identifies tumors with metastatic potential. Oncogene 28 2796-2805. (doi:10.1038/onc.2009.139)

Naderi M, Wong MY \& Gholami F 2014 Developmental exposure of zebrafish (Danio rerio) to bisphenol-S impairs subsequent reproduction potential and hormonal balance in adults. Aquatic Toxicology 148 195-203. (doi:10.1016/j.aquatox.2014.01.009)

Ochi T 1999 Induction of multiple microtubule-organizing centers, multipolar spindles and multipolar division in cultured V79 cells exposed to diethylstilbestrol, estradiol-17beta and bisphenol A. Mutation Research 431 105-121. (doi:10.1016/S00275107(99)00190-6)

Ogden A, Rida PC \& Aneja R 2013 Heading off with the herd: how cancer cells might maneuver supernumerary centrosomes for directional migration. Cancer and Metastasis Reviews 32 269-287. (doi:10.1007/s10555-012-9413-5)

Pfeiffer E, Rosenberg B, Deuschel S \& Metzler M 1997 Interference with microtubules and induction of micronuclei in vitro by various bisphenols. Mutation Research 390 21-31. (doi:10.1016/S01651218(96)00161-9)

Pihan GA 2013 Centrosome dysfunction contributes to chromosome instability, chromoanagenesis, and genome reprograming in cancer. Frontiers in Oncology 3 277. (doi:10.3389/fonc.2013.00277)

Pihan GA, Purohit A, Wallace J, Malhotra R, Liotta L \& Doxsey SJ 2001 Centrosome defects can account for cellular and genetic changes that characterize prostate cancer progression. Cancer Research $\mathbf{6 1}$ 2212-2219

Pihan GA, Wallace J, Zhou Y \& Doxsey SJ 2003 Centrosome abnormalities and chromosome instability occur together in preinvasive carcinomas. Cancer Research 63 1398-1404.

Prins GS, Hu WY, Shi GB, Hu DP, Majumdar S, Li G, Huang K, Nelles JL, Ho S-M \& Walker CL 2014 Bisphenol A promotes human prostate stem-progenitor cell self-renewal and increases in vivo carcinogenesis in human prostate epithelium. Endocrinology 155 805-817. (doi:10.1210/en.2013-1955)

Rogers JA, Metz L \& Yong VW 2013 Review: endocrine disrupting chemicals and immune responses: a focus on bisphenol-A and its potential mechanisms. Molecular Immunology 53 421-430. (doi:10.1016/j.molimm.2012.09.013)

Ruan T, Liang D, Song S, Song M, Wang H \& Jiang G 2015 Evaluation of the in vitro estrogenicity of emerging bisphenol analogues and their respective estrogenic contributions in municipal sewage sludge in 
China. Chemosphere 124 150-155. (doi:10.1016/j. chemosphere.2014.12.017)

Song S, Song M, Zeng L, Wang T, Liu R, Ruan T \& Jiang G 2014 Occurrence and profiles of bisphenol analogues in municipal sewage sludge in China. Environmental Pollution 186 14-19. (doi:10.1016/j. envpol.2013.11.023)

Tang WY, Morey LM, Cheung YY, Birch L, Prins GS \& Ho SM 2012 Neonatal exposure to estradiol/bisphenol A alters promoter methylation and expression of Nsbp1 and Hpcal1 genes and transcriptional programs of Dnmt3a/b and Mbd2/4 in the rat prostate gland throughout life. Endocrinology 153 42-55. (doi:10.1210/en.2011-1308)

Tarapore P \& Fukasawa K 2000 p53 mutation and mitotic infidelity. Cancer Investigation 18 148-155. (doi:10.3109/07357900009038246)

Tarapore P, Okuda M \& Fukasawa K 2002 A mammalian in vitro centriole duplication system: evidence for involvement of CDK2/ cyclin E and nucleophosmin/B23 in centrosome duplication. Cell Cycle 1 75-81. (doi:10.4161/cc.1.1.103)

Tarapore P, Hanashiro K \& Fukasawa K 2012 Analysis of centrosome localization of BRCA1 and its activity in suppressing centrosomal aster formation. Cell Cycle 11 2931-2946. (doi:10.4161/cc.21396)

Tarapore P, Ying J, Ouyang B, Burke B, Bracken B \& Ho SM 2014 Exposure to bisphenol A correlates with early-onset prostate cancer and promotes centrosome amplification and anchorage-independent growth in vitro. PLoS ONE 9 e90332. (doi:10.1371/journal.pone.0090332)

Vandenberg LN 2014 Non-monotonic dose responses in studies of endocrine disrupting chemicals: bisphenol A as a case study. Dose Response 12 259-276. (doi:10.2203/dose-response.13-020. Vandenberg)

Vandenberg LN, Colborn T, Hayes TB, Heindel JJ, Jacobs DR Jr, Lee DH, Shioda T, Soto AM, vom Saal FS \& Welshons WV et al. 2012 Hormones and endocrine-disrupting chemicals: low-dose effects and nonmonotonic dose responses. Endocrine Reviews 33 378-455. (doi:10.1210/er.2011-1050)

Vinas R \& Watson CS 2013 Bisphenol S disrupts estradiol-induced nongenomic signaling in a rat pituitary cell line: effects on cell functions. Environmental Health Perspectives 121 352-358. (doi:10.1289/ehp.1205826)
Vinas P, Campillo N, Martinez-Castillo N \& Hernandez-Cordoba M 2010 Comparison of two derivatization-based methods for solid-phase microextraction-gas chromatography-mass spectrometric determination of bisphenol A, bisphenol S and biphenol migrated from food cans. Analytical and Bioanalytical Chemistry 397 115-125. (doi:10.1007/s00216-010-3464-7)

vom Saal FS, Akingbemi BT, Belcher SM, Birnbaum LS, Crain DA, Eriksen M, Farabollini F, Guillette LJ, Hauser R, Heindel JJ, et al. 2007 Chapel Hill bisphenol A expert panel consensus statement: integration of mechanisms, effects in animals and potential to impact human health at current levels of exposure. Reproductive Toxicology 24 131-138. (doi:10.1016/j.reprotox.2007.07.005)

Wang W, Abualnaja KO, Asimakopoulos AG, Covaci A, Gevao B, Johnson-Restrepo B, Kumosani TA, Malarvannan G, Minh TB, Moon H-B, et al. 2015 A comparative assessment of human exposure to tetrabromobisphenol A and eight bisphenols including bisphenol A via indoor dust ingestion in twelve countries. Environment International 83 183-191. (doi:10.1016/j. envint.2015.06.015)

Yan X, Habedanck R \& Nigg EA 2006 A complex of two centrosomal proteins, CAP350 and FOP, cooperates with EB1 in microtubule anchoring. Molecular Biology of the Cell 17 634-644. (doi:10.1091/ mbc.E05-08-0810)

Yang Y, Guan J, Yin J, Shao B \& Li H 2014 Urinary levels of bisphenol analogues in residents living near a manufacturing plant in south China. Chemosphere 112 481-486. (doi:10.1016/j. chemosphere.2014.05.004)

Zawatski W \& Lee MM 2013 Male pubertal development: are endocrinedisrupting compounds shifting the norms? Journal of Endocrinology 218 R1-R12. (doi:10.1530/JOE-12-0449)

Zhou X, Kramer JP, Calafat AM \& Ye X 2014 Automated on-line columnswitching high performance liquid chromatography isotope dilution tandem mass spectrometry method for the quantification of bisphenol A, bisphenol F, bisphenol S, and 11 other phenols in urine. Journal of Chromatography B: Analytical Technologies in the Biomedical and Life Sciences 944 152-156. (doi:10.1016/j. jchromb.2013.11.009)

Received in final form 15 December 2016

Accepted 19 December 2016

Accepted Preprint published online 20 December 2016
() 2017 Society for Endocrinology Printed in Great Britain
Published by Bioscientifica Ltd 